\title{
Employing Evidence in Evaluating Complementary Therapies: Findings from an Ethnography of Integrative Pain Management at a Large Urban Pediatric Hospital
}

\author{
Isabel Roth, DrPH, Linda Highfield, $\mathrm{PhD}^{2}$ Paula Cuccaro, $\mathrm{PhD}^{3}$ Rebecca Wells, $\mathrm{PhD}^{2}$ \\ Sanghamitra Misra, MD, ${ }^{4}$ and Joan Engebretson, $\mathrm{DrPH}^{5}$
}

\begin{abstract}
Background: Complementary and Integrative Medicine (CIM) shows positive clinical benefit with minimal side effects, yet, challenges to effective integration of CIM providers in biomedical health care settings remain. This study aimed to better understand the role evidence played in the process of integration of complementary therapies into a large urban pediatric hospital from the perspective of patients, caregivers, providers, and administrators through applied medical ethnography.

Methods: An ethnography was conducted over the course of 6 months in a large urban pediatric hospital in the Southern United States. At the time, the hospital was piloting an integrative medicine (IM) pain consult service. Purposive sampling was used to select providers, patients, administrators, and caregivers to follow as they engaged with both the preexisting pain service and pilot IM pain services. Field observation and interviews were conducted with 34 participants. Thematic content analysis was used to analyze field notes, interview transcripts, and documents collected.

Findings: Analysis of the data revealed five themes regarding the role of evidence in the process of integration: Anecdotal Evidence and Personal Experience Effecting CIM Use, Open to Trying Whatever Works, Resistance to the Unfamiliar, Patients and Parents Trusting Doctors as Experts, and Importance of Scientific Evidence to Biomedicine. All themes address the role of evidence in relationship to acceptance of complementary therapies and correspond with three thought processes: critical thinking, relying on others for evidence, and reactionary thinking.

Conclusion: Both scientific and anecdotal evidence informed CIM use in this context. Biomedical environments seeking to integrate CIM into pain treatment regimens will need to engage all relevant stakeholders in building education, clinical training, and research programs that are critically informed about the context and evidence for CIM.
\end{abstract}

Keywords: complementary therapies, integrative medicine, pain management, ethnography, qualitative methods, pediatric

\footnotetext{
${ }^{1}$ Program on Integrative Medicine, Department of Physical Medicine and Rehabilitation, University of North Carolina at Chapel Hill School of Medicine, Chapel Hill, NC.

Departments of ${ }^{2}$ Management, Policy, and Community Health and ${ }^{3}$ Health Promotion and Behavioral Science, University of Texas Health Science Center School of Public Health (UTHealth), Houston, TX.

${ }^{4}$ Department of Academic General Pediatrics, Baylor College of Medicine, Houston, TX.

${ }^{5}$ Department of Family Health, University of Texas Health Science Center Cizik School of Nursing (UTHealth), Houston, TX.

An earlier version of this abstract was presented at the International Congress of Integrative Medicine \& Health Academic Consortium, Baltimore, MD, May 8-11, 2018.
} 


\section{Introduction}

A S MANY AS THREE QUARTERS of hospitalized children experience pain in a given $24-h$ period. ${ }^{1}$ Pain in children can lead to missed school days and severe emotional distress during critical developmental phases. ${ }^{2}$ Opioid analgesics are one of the most common treatments for pain. ${ }^{3}$ With deaths from opioid misuse up $400 \%$ since $1999,{ }^{4}$ almost half a million adolescents in the United States using opioids nonmedically, ${ }^{5}$ and poisoning deaths from prescription drug use among teens aged 15-19 increasing from $30 \%$ of all poisoning deaths in 2000 to $57 \%$ of all poisoning deaths in $2009,{ }^{6}$ nonpharmacologic pain management strategies are urgently needed, particularly for children and adolescents.

Complementary and Integrative Medicine (CIM) shows positive clinical benefit with minimal side effects, yet, challenges to effective integration of CIM providers in biomedical health care settings remain. ${ }^{7}$ Improved integration of CIM providers into pediatric pain treatment regimens has the potential to mitigate opioid use, improve pain control, and reduce the number of adverse events due to pain treatment.

CIM refers to a wide range of practices, typically including mind-body modalities such as yoga, meditation, acupuncture, and massage, and natural products such as dietary supplements, herbs, homeopathic remedies, tinctures, and teas. The term "complementary" implies in addition to western or conventional medicine, "alternative" suggests using these therapies instead of conventional medicine, while the term "integrative" conveys a collaboration between complementary and allopathic providers. ${ }^{8}$

In $2012,33 \%$ of the total U.S. adult population had used at least one form of complementary and alternative medicine (CAM) in the previous year. ${ }^{9}$ Data from the National Health Interview Survey show that CAM use among children ages 4-17 has remained consistent at $12 \%$ of the population annually in both 2007 and 2012, and children chiefly use CAM practices to treat pain. ${ }^{10}$ Among children with pain, $21 \%$ use CAM annually. ${ }^{11} \mathrm{CIM}$ approaches are increasingly being recognized as both efficacious and effective treatments for pain for both children and adults, ${ }^{2,12-14}$ leading major medical associations to recommend the incorporation of nonpharmacologic pain management strategies, ${ }^{15}$ and the joint commission to now require that these services be made available. $^{16}$

Medical hypnosis, music therapy, and acupuncture are particularly noteworthy in terms of their clinical benefit and safety profiles for controlling and treating pain. There is very strong evidence indicating medical hypnosis as an appropriate treatment for anticipatory anxiety and to control pain. ${ }^{17,18}$ Music therapy has shown positive impact on quality of life in hospital patients, improved patient satisfaction, and both anxiety and pain reduction. ${ }^{19-21} \mathrm{~A}$ review of the acupuncture literature suggests positive evidence supporting the use of acupuncture for both acute and chronic pain in the pediatric population. ${ }^{22}$ While adverse events have been reported, acupuncture is considered safe when performed by properly trained practitioners. ${ }^{23}$

Increasingly, CIM is being successfully implemented in pediatric hospital settings globally, ${ }^{24,25}$ with findings beginning to point to lessons that can be applied in the implementation of CIM more broadly. Yet, there are clear challenges that have been documented in introducing a new integrative medicine (IM) program into an academic medical center, such as financial barriers and countering entrenched biases among practitioners trained in differing medical paradigms. 7,26

Ethnographies of integrative health care models in adult settings have revealed social, professional, and ideologic challenges between biomedical practitioners and CAM providers. $^{27,28}$ The prioritization of biomedical evidence over traditional knowledge bases from CAM disciplines, and further, the reinterpretation of that traditional knowledge by biomedicine has been called "paradigm assimilation," pointing to the complexity of evidence use and interpretation in the process of integration. ${ }^{29}$ However, recognizing the potential for subjugation of CAM knowledge still leaves those who wish to integrate without a roadmap for doing so responsibly and successfully.

Much of the research on integration of CAM into the biomedical environment has focused on the perspectives of health care providers, leading past researchers to call for the incorporation of additional perspectives. ${ }^{30,31}$ Parent and pediatric patient outlooks may be particularly informative in the development of a patient-centered pediatric health initiative. $^{32}$ Parent sociobehavioral characteristics, such as demographics, values, and beliefs, have been previously demonstrated to play a role in their decision-making regarding CAM use for children, pointing to the individual dynamics under consideration in CAM use. ${ }^{33}$

This study aimed to better understand the process of integration of complementary and integrative therapies into a large urban pediatric hospital from the perspective of patients, caregivers, providers, and administrators through applied medical ethnography. As these individuals consider innovation, they must weigh available evidence about potential benefits and harm. This article focuses on the role that evidence played in the process of integration in the pediatric hospital context.

\section{Methods}

This study, an applied medical ethnography, ${ }^{34}$ consisted of participant observation, formal and informal participant interviews, and document review. It was conducted at a large urban pediatric hospital in the southern United States for a 6-month study period, from January to July 2017. An Integrative Medicine Pain Consult Service (IM pilot) had been developed and was planned at the hospital in the months before the study period and was piloted from April to July of $2017 .{ }^{35}$ The IM pilot was being tested for feasibility at the time of the ethnography (Fig. 1).

A multidisciplinary pain team under the department of anesthesiology had been in place for 2 years before the study period. This pain team ran an outpatient pain clinic, which included physical therapy, psychologic services, acupuncture, biofeedback, and guided imagery, as well as an inpatient pain consult service. Most consults for the inpatient pain service were from immediately postsurgical patients. The IM pilot team recruited participants who had already consulted the existing inpatient pain service. Patients were then offered the opportunity to enroll in the IM pilot and receive up to two additional services to address their pain, including music therapy, acupuncture, biofeedback, medical hypnosis, guided imagery, and guided meditation. 


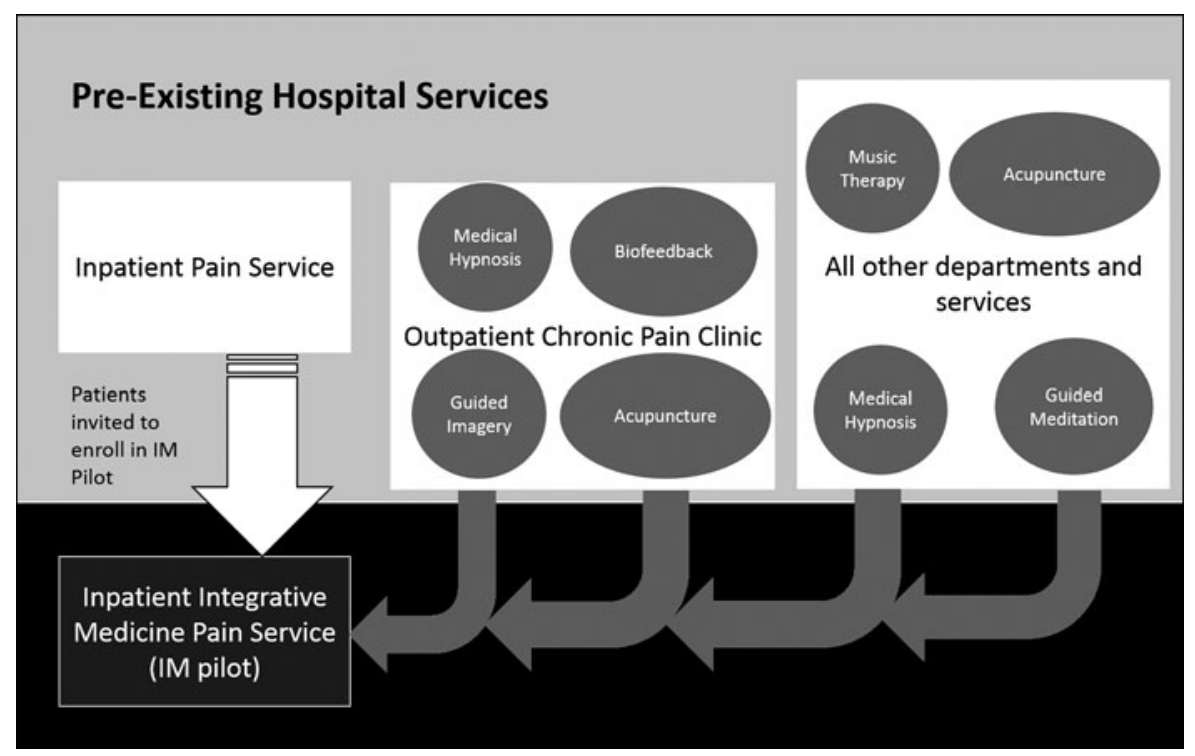

FIG. 1. Schema of referrals from existing pain and related services to IM pilot. Clinics and services are indicated using rectangles. Arrows describe the flow of patients and providers from departments and services to the IM pilot. Complementary therapies are shown using ovals. Background shading is used to distinguish between preexisting hospital services, and the new service being tested for feasibility. IM, integrative medicine.

All providers who participated in the IM pilot worked in various departments throughout the inpatient and outpatient arms of the hospital. These providers individually offered at least one of the services in their own clinical practice. They included physicians, nurse practitioners, psychologists, and complementary therapists, and all had professional credentials in the modality they were practicing. Two members of the team were pain specialists who also worked with the multidisciplinary pain team. Although all complementary therapies had been available to some outpatients and inpatients before the study, the IM pilot feasibility study was the first collaboration of these CIM providers to create a new IM inpatient consult service and systematically offer these services to inpatients.

The principal investigator of the IM pilot and the ethnographer had a previous research relationship and collaborated to design the ethnography as a complement to the IM pilot feasibility study. This helped facilitate the entry of the ethnographer into the clinical environment. Field observation began, following approval by the Institutional Review Boards of both the researcher's home institution and the IM pilot investigator's institution. During the 23 week study period, the ethnographer spent between 5 and $30 \mathrm{~h}$ per week conducting fieldwork, resulting in roughly $200 \mathrm{~h}$ of fieldwork. The fieldwork included shadowing providers during their inpatient and outpatient sessions, attending resident education sessions focused on CAM, participating in select activities (i.e., music group), and attending IM pilot research meetings. 36

During the fieldwork process, key informants provided ongoing interpretation and clarification of emerging themes. ${ }^{34}$ Key informants included IM pilot team members who were shadowed throughout their workdays and who explained their activities and work relationships in detail.

Purposive sampling was used to select providers, patients, and caregivers to follow as they engaged with the pain service and IM services. ${ }^{37}$ Once the IM pilot began, families who qualified for participation in the IM pilot were invited to be interviewed as part of the ethnography. The majority of the IM pilot participants agreed to be interviewed. In addition, some families who declined to participate in the IM pilot chose to be interviewed. An emergent interview guide was used to guide in-depth, open-ended interviews with providers, parents, patients, and administrators (Appendices A1 and A2). Sampling continued until thematic saturation was achieved. ${ }^{38}$

Thirty-four participants were interviewed formally and informally over the course of the study period. Informal interviews were unrecorded conversations, in which the ethnographer clarified observations with participants. All

TABle 1. Interview Participants

\begin{tabular}{lccccc}
\hline & $\begin{array}{c}\text { Recorded and } \\
\text { transcribed } \\
\text { interviewees, N }\end{array}$ & $\begin{array}{c}\text { Informal } \\
\text { interviewees, N }\end{array}$ & \% female & \% White & $\begin{array}{c}\text { \% racial or } \\
\text { ethnic minority }\end{array}$ \\
\hline Caregivers & 8 & 4 & 100 & 25 & 75 \\
Patients & 7 & - & 14 & 14 & 86 \\
Providers & 6 & 4 & 90 & 50 & 50 \\
Administrators & 2 & 3 & 75 & 42 & 50 \\
Total & 23 & 11 & 70 & \\
\hline
\end{tabular}

A total of 34 interviews were conducted, with 23 participants engaging in formal recorded interviews and an additional 11 participants engaging in informal interviews. Overall, $75 \%$ of participants identified as female and $58 \%$ of participants identified as racial or ethnic minorities. 
participants are referred to by pseudonyms. Eleven parents, 1 grandparent, 7 pediatric patients, 10 providers, and 5 administrators were interviewed over the course of the ethnography (Table 1).

All of the administrators either directly or indirectly supervised one or more of the providers participating in the IM pilot. Of the providers interviewed, six were part of the IM pilot, and two were part of the pain team but not directly involved in the pilot, and two were training in IM, but not directly involved in the pilot (Table 2). All the pediatric patients were interviewed with their parents present. The pediatric patients interviewed ranged in age from 7 to 19 with a mean age of 11.42. The ethnic diversity represented in the patient and parent participants approximated that of the inpatient population in this urban hospital context.

Field notes and analytic memos from field observations were recorded following observation and interviews. All interviews were recorded with a digital voice recorder and sent to an encrypted transcription service. ${ }^{39}$ Transcripts were then validated by the ethnographer and uploaded into ATLAS.ti software for data management. Data were stored on an encrypted hard drive and cloud drive. All notes, interview transcripts, codes, and memos were maintained in the ATLAS.ti database.

Notes from field observation as well as informal and formal interviews were coded and analyzed iteratively throughout the research project by the ethnographer using thematic content analysis and framework analysis, which included mapping themes and related data into an emergent framework. ${ }^{40,41}$ During data collection and analysis, concepts and themes were verified and clarified with participants during interviews, and in some cases, in follow-up interviews. Reflexivity was exercised through continuous analytic memoing. Debriefing was facilitated by J.E., an experienced qualitative researcher where codes and other results were checked for congruency.

Codes and analytic memos were continuously revised and updated. Coding was conducted by the ethnographer and verified with the assistance of an experienced qualitative researcher. ${ }^{42}$ Code mapping, in which codes were organized by their relationships to one another, and landscaping, in which codes were grouped and further organized into subcodes, were used to organize codes and assess their relationships to one another. ${ }^{42}$ Codes were grouped into "families" to identify subthemes and themes. ${ }^{42}$ Information gleaned from participant observation, including field notes and analytic memos, and interviews with providers, administrators, patients, and parents were triangulated during analysis to create a holistic sense of the use of CIM at the hospital.

\section{Findings}

Analysis of the data revealed five themes regarding the role of evidence in the process of integration: (1) Anecdotal Evidence and Personal Experience Effecting CIM Use, (2) Open to Trying Whatever Works, (3) Resistance to the Unfamiliar, (4) Patients and Parents Trusting Doctors as Experts, and (5) Importance of Scientific Evidence to Biomedicine. These themes were present for all groups interviewed, but some were more pronounced for certain constituencies. All themes from the current data relate to the role of evidence in relationship to cultural acceptance of complementary therapies and can be organized based on how evidence is used in shaping decision-making around CIM (Fig. 2).

Three thought processes correspond with the themes from these data: critical thinking, relying on others for evidence, and reactionary thinking. Critical thinking was associated with Anecdotal Evidence and Personal Experience Effecting CIM Use and Importance of Scientific Evidence to Biomedicine. Both themes reflect participants' dialectical engagement with a form of evidence, be it anecdotal or scientific. Open to Trying Whatever Works and Patients and Parents Trusting Doctors as Experts were both associated with relying on others for evidence. Both themes reflect the tendency for families to defer medical decision-making to health care providers.

Finally, Resistance to the Unfamiliar was associated with reactionary thinking, in which participants had an automatic reaction to the idea of using a complementary therapy, but there was no evidence of critical discourse. Participants exhibited multiple thought processes; for one patient, acupuncture elicited reactionary thinking, while all other complementary therapies evoked a reliance on others for evidence. These themes illustrate the construction of evidence by patients, caregivers, providers, and administrators.

\section{Anecdotal evidence and personal experience affecting CIM use}

Participants described word of mouth and personal experience as the primary modes for building support for CIM. All the providers discussed word of mouth as an important tool for garnering support for the complementary therapies they practice, among both the patients and other providers who were seeing positive results in their patients. One of the IM pilot providers, Sarah, was aware that locating the IM pilot within the hospital would not only help bring CIM to more people but also would lend the prestige associated with

Table 2. Complementary Therapies Practiced by Integrative Medicine Pilot Team

\begin{tabular}{lcccccc}
\hline & Acupuncture & Biofeedback & Hypnosis & Guided imagery & Music therapy & Meditation \\
\hline Pediatrician & - & - & - & $\mathrm{X}$ & - \\
Anesthesiologist & $\mathrm{X}$ & - & - & - & - \\
Rheumatologist & $\mathrm{X}$ & - & - & $\mathrm{X}$ & $\mathrm{X}$ \\
Music therapist & - & $\mathrm{X}$ & $\mathrm{X}$ & $\mathrm{X}$ & - \\
Pain psychologist & - & - & $\mathrm{X}$ & - & - \\
Nurse practitioner & - & - & - \\
\hline
\end{tabular}

Members of the IM pilot had a range of professional identities, including subspecialists in medicine, music therapy, and nursing practice. IM pilot providers were also trained in one or more of the complementary therapies being offered as part of the IM pilot.

IM, integrative medicine. 
Employment of Evidence in Evaluating Complementary Therapies

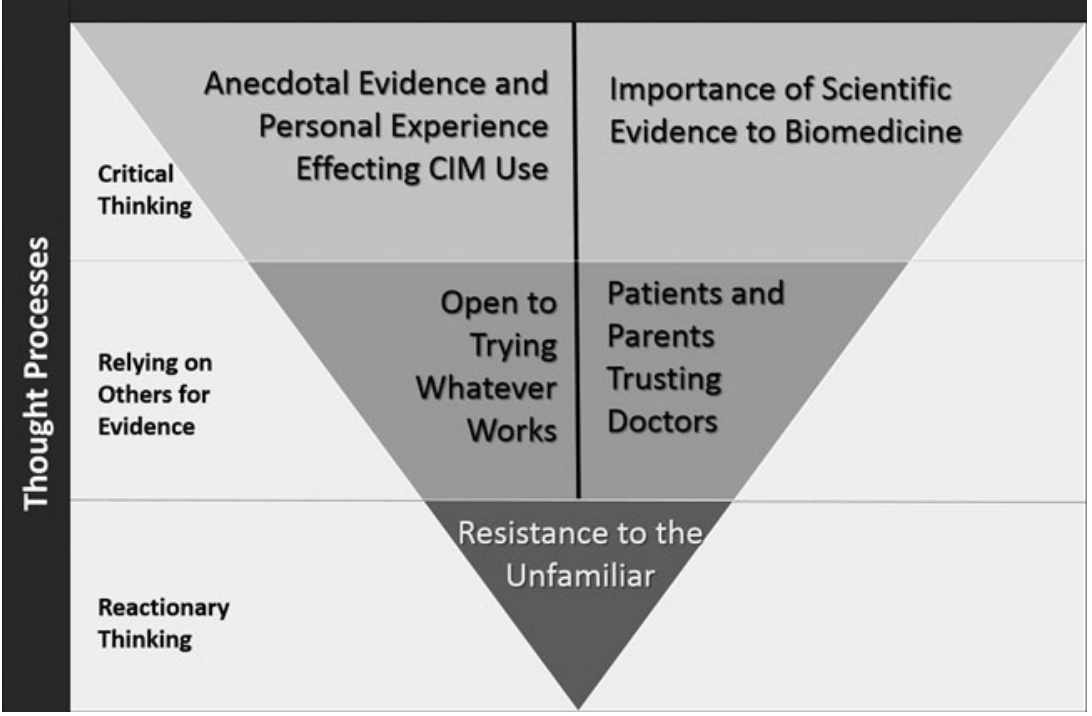

FIG. 2. The role of evidence in the process of integration. Themes related to using evidence for complementary therapies are shown inside the triangle. The themes are organized by corresponding thought processes, which are indicated vertically. the hospital to CIM modalities that patients might have been skeptical of previously. She described stimulating conversation as one of the goals of the IM pilot.

Sarah: "I think part of the goal is simply to introduce CIM to the community, and we are doing that one patient at a time. We hope that our patients are going out and saying, 'oh, well if at [this Hospital] they're interested, you know, they believe that this can help my pain. Look, if I have chronic pain, or I know someone else that has pain, I'll let them know that, well, I did acupuncture. Or I did guided imagery, and it was helpful.',

Many of the providers, parents, and one of the administrators described their personal use of CIM affecting their understanding of its utility. While most participants were aware of various CIM modalities, their personal experiences shifted their opinions and enthusiasm about the effects of complementary therapies. Michelle, another of the IM pilot providers, described the hands-on experience she gave to her boss as transformational. While Michelle's boss had supported her acupuncture practice regardless of his personal biases, it was not until he experienced acupuncture for himself that he actually believed in its clinical effectiveness.

Michelle: "So my boss... asked me to show him acupuncture, what it was like. And he wanted to get pictures to put into, to the newsletter to show people what I was doing. My boss-like I said, 'you know, I need to plan a therapy plan for you. What's going on today that I can help you with?' And he's like, 'well I have a headache.' And I said, 'okay, well I have some points that I want to like to set up for you'... when I was inserting the needles, he was like shocked that he was like feeling these things, and he was just amazed by it. And he goes-he's like, 'I have a confession to make.' He's like, 'I really didn't think this was going to work, and I didn't really know anything about acupuncture. But—and it was more for press, but [laughs] I actually was surprised at how really awesome it was for me [laughs].' ...He just wasn't expecting to have any sort of response to it. And he was just amazed when I was putting the needles in of what he was feeling. He was like, "whoa [laughs] wow'...I made him a believer.'
Michelle's example illustrates the power of personal experience for shifting preconceived notions of CIM. Her boss' comments indicate that he believed acupuncture was a popular fad with no substantial therapeutic effect. These attitudes reflect the gulf between the depiction of complementary therapies in the popular press, and many medical professionals' lack of exposure to scientific evidence or education on these therapies.

For parents, it was information from books, other parents, family, or their own personal experience that shaped their orientation toward CIM. Amanda, the mother of Paul, a 9year-old boy recovering from a surgery, spoke about the massage, meditation, music therapy, and yoga she and her husband used at home to help her children.

Amanda: "For us we've always known as, my husband and I, as a team, that we're never going to have even one fraction of the amount of answers we need. And so we're always trying to read up on something else or talk with another family and just really say, 'Okay. So, your kiddo is experiencing this, or not experiencing anything. But, what do you do? How do you... What does that look like to parent in your house?,",

Amanda's comments speak to the relative acceptance of complementary therapies in popular culture, and relying on others in the community to inform choices about which modalities to use. Her comments reflect not only an openness and curiosity about complementary therapies but also a respect for the expertise of her friends and neighbors. This reliance on anecdotal evidence was mentioned frequently by caregivers and reflects the particular importance of advice from a trusted member of the community.

\section{Open to trying whatever works}

Families dealing with acute pain: let's try all options. Families dealing with acute pain spoke about being open to whatever treatments would provide some relief. Taylor, a 19-year-old patient said, "I mean, I'm, I'm open minded. Yeah. As long as it won't hurt me that'll be fine." Julie, whose son was recovering from a partial leg amputation, 
also elaborated on her openness to recommendations from others.

Julie: "We're just, pretty much just open to try anything. That, if people have, like, advice about it. Like, different things that they can tell us to try. We are just-we're open to trying it. I don't really know what all there is, but-if there's-if somebody knows something...I mean, we're okay with trying it."

Emily, whose 17-year-old son Colt had been in a serious accident and was recovering from surgery, spoke about her openness to making use of all available healing techniques. In particular, the idea of using a complementary therapy in addition to pharmacologic pain management seemed like a "best of both worlds" approach.

Emily: "I just think the mind is pretty powerful. And I also think there's a lot of stuff we don't know. So, even like when you talk about like the power of prayer, even if it's something that makes somebody feel better, it still makes somebody feel better. So, I just always feel like, who am I to say something doesn't work?"

For the families dealing with acute pain, they contextualized their openness to CIM as utilizing all available options. Most families did not feel expert in their knowledge of CIM, and few engaged directly with the scientific literature, but were curious to learn about it and eager for advice.

Families dealing with chronic pain: searching for an answer. Heather, a nurse specializing in pain management, provided some context about the fatigue among families she sees in the chronic pain clinic; "By the time they get to us, they've been to a lot of people already." The families who had been dealing with chronic pain were also open and eager to use some CIM treatments, but had wariness regarding medicine and new treatments in general. Carina, whose 11year-old son was suffering from chronic abdominal migraines, was not only open to trying anything but also was dogged in her pursuit of a treatment that would help her son. When she heard that acupuncture was being offered at the hospital, she tracked down Michelle to schedule an outpatient visit for her son. Families dealing with both chronic and acute pain were looking for solutions and were interested in having as many effective options as possible made accessible to them.

\section{Resistance to the unfamiliar}

Providers who had been practicing complementary therapies within the hospital environment the longest spoke about the resistance they had encountered over the years. Catherine, a provider trained in medical hypnosis, had struggled with her supervisor when she first brought hypnosis into the clinical setting. She found that acceptance had grown over time as she had more and more positive outcomes with patients, and the other providers in her clinic increasingly turned to her to help with their hardest-to-treat patients.

Catherine: "There was a huge resistance here initially. Um, it - culturally, that this was not real medicine. This was not real therapy. This was, um, voodoo. Yeah. But it-it's gotten better in the last eight years."

Gabriela, a pain specialist who also provides clinical hypnosis, had noticed similar fears from some of the families of children with chronic pain who she worked with. To Gabriela, it seemed that the word "hypnosis" conjured popular images that automatically alienated families, and she had to work to convince them that this could be a clinically efficacious treatment.

Gabriela: "Sometimes in terms of medical hypnosis specifically, there's some fears about, 'Oh, what is that? Is that, like, you know, when you swing a pendulum in front of my face?' Um, that's something, I guess, mystical or creepy about that. And so, um, for that modality specifically, sometimes there's a little bit more explanation or calling it something else, um, the just - the term itself, I think can be kind of scary for some families and kids...Like, 'that won't work,' or something like that...Um, I think there's a bit more bias here towards, uh, what we think of as more traditional medical interventions like medical procedures, um, a little bit less openness to complementary medicine."

Fear or negative bias was most commonly reported for hypnosis and acupuncture. There was particular concern about acupuncture causing or exacerbating pain, particularly associated with needles.

Taylor said "Acupuncture was, that was the one that was the one that was a no-go for me...To me, needles-...hurt me, so... Let's close off that one. But all the other ones are fine."

For Taylor and other patients, the idea of needles being used had enough negative associations to turn them off from learning more about acupuncture. The concerns raised by families and reported by providers came from mostly anxiety. When discussing the negative potential of CIM modalities, negative scientific evidence was never mentioned.

\section{Patients and parents trust doctors as experts}

When discussing decision-making regarding pharmacologic pain management, patients and parents with children in acute pain immediately spoke about trusting their doctors. Jessie, a 13-year-old patient who was postsurgical said "I mean, they just give me the pain medication and I take it. I mean, I think that without the medicine it would be like, bad." Taylor, a 19-year-old patient who had also just had surgery had similar comments about his pain medications; "I trust them... They said we're going to put you on this. I was like, okay." Julie, the mother of Jace, a 7-year-old who had just had an amputation, also expressed full trust in the doctors to manage her son's acute pain.

Julie: "So I think I trust them with their judgment on what type of meds he should be on...I just want him, I don't want him in any pain, especially being that he's had his legs amputated, of course. Maybe if it was something a little bit smaller, another smaller procedure, maybe it'd be different. But with this, I pretty much trusted their judgment on what to give him."

Julie felt that given the complexity of Jace's condition, she would cede most decision-making to the medical team, whom she trusted as experts. Sarah, a pediatrician, spoke about relying on this trust and building on the cultural acceptance of medical professionals as experts to build support for CIM.

Sarah: "I think they trust us...if they see physicians are endorsing them, or endorsing certain practices, they may be more willing to try it."

Sarah and the other members of the IM pilot team were very aware that the credibility presented by the hospital and 
its reputation served as an endorsement of the complementary therapies they offered. The physicians in the group referred to themselves as "physicians first," recognizing that the medical training they received is what gave them the most social capital in a biomedical context.

\section{Scientific evidence matters to biomedicine}

All the providers and administrators spoke about the importance of scientific evidence. Providers engaged in frequent clinical education of medical students and residents, and in speaking about CIM in general or the modality they practiced specifically, they would cite numerous studies. In formal lectures, such as resident education sessions, this would take the form of an exhaustive summary of available evidence of complementary therapies. In the clinical setting, providers would cite studies from memory, showing how frequently they speak about research and how familiar they are with it. Albert, a clinical chief and the chair of his department, said he was skeptical of therapies that do not have evidence of effectiveness; "we're not going to smear mustard oil on 100 people's chests if it isn't helping them."

Albert was supportive of the IM pilot, and served as Sarah's mentor. He wanted to be sure that the hospital was only associating itself with rigorously researched practices. His advice had resonated with Sarah. She was aware that to make the IM pilot a success, she would have to navigate the entrenched biases that exist within the medical hierarchy, and the most effective way to do this was by using evidence. In referencing the lack of perceived evidence for healing touch and why the team had decided not to include it in the pilot, Sarah said 'I don't want to bring really controversial modalities. Let's just implement those modalities now that we have plenty of evidence for."

CIM providers were not just interested in there being sufficient peer-reviewed evidence that they themselves could be satisfied that CIM modalities being practiced in the hospital were safe and effective. The IM pilot team was concerned with the perception of the available evidence by the biomedical community and recognized that a modality that could be perceived as controversial could be detrimental to their efforts to build an IM program.

\section{Discussion}

The findings of the current study have been constructed into a framework for understanding how evidence factors in during the process of integration in a pediatric hospital setting. In-depth interviews conducted with a range of stakeholder groups, including patients, caregivers, providers, and administrators, provide a holistic set of perspectives of the environment under study. The thought processes identified deal with engagement with evidence, or a lack thereof. The findings presented in this study suggest that when engagement with various types of evidence is maximized, buy-in and implementation of IM can be enhanced.

\section{Critical thinking}

The current findings demonstrate that biomedical evidence, anecdotal, and experiential evidence influence stakeholders' engagement with CIM. While biomedical evidence is often prioritized by those trained in a biomedical paradigm, as previous inquiries have noted, ${ }^{29}$ administrators, providers, and parents in the current study reported their lived experiences as affecting their decisions to use CIM. The finding that the providers are applying critical thinking, considering a range of evidence sources to inform decisionmaking, is consistent with clinical training. Of note is that parents also demonstrated this approach to making decisions about CIM for their children. Application of critical thinking allows for the consideration of nuance and complexity.

\section{Relying on others for evidence}

With families, and the desperation that can accompany a child being sick, the health care provider's opinion can hold substantial power, arguably too much. Relying on others for evidence may be unavoidable, in both the acute and chronic pain contexts. Research on shared decision-making between medical providers and patients has revealed that increased health care knowledge is not the same thing as patients feeling empowered in decision-making contexts. ${ }^{43}$ Biomedically trained providers were cognizant of the power and influence they carried because of their profession. In supporting uptake of IM, the evidence found here suggests that endorsement and support by physicians and nurses of IM inherently influences families.

\section{Reactionary thinking}

Otherwise stated, reactionary thinking is a lack of engagement with critical thought processes. Examples of physicians, parents, and pediatric patients exhibiting reactionary thinking in the current data point to a low but noteworthy prevalence of this type of thinking. While there was evidence of reactionary thinking, the findings also suggest that this type of thinking was decreasing over time. Resistance to IM in biomedical environments ${ }^{27,44}$ has been repeatedly documented in the literature and may never completely go away.

Anyone working in IM needs to be cognizant of opposition based on unfamiliarity. Biomedicine remains the dominant medical paradigm in the United States. Although complementary therapies are becoming more integrated and there is more exposure and education, biomedical dominance may be assumed. ${ }^{29}$ The lesson for IM providers is to anticipate this reaction and to be prepared to educate. The providers observed in the current study used a combination of research presentation and offering hands-on experiences to ease the introduction of IM.

\section{Limitations}

The ethnographic method can be limited by the unique perspective of the ethnographer, although triangulation of data from multiple sources can enhance the rigor of this approach. $^{37}$ The number and engagement of participants, many of whom were discharged within a day or two of receiving treatment from the IM pilot team, limited this study. Many families were exhausted and overwhelmed during their hospital stay and declined to participate for this reason.

The current study represents the reflections of participants at one pediatric hospital environment, and while lessons learned may be of interest, the results presented here may 
not be applicable to other settings. The ethnographer gained entry into the field through the leader of the IM pilot, and all participants were either directly or indirectly involved in the IM pilot. Additional perspectives from those not associated with IM, but still part of the hospital environment, would have provided additional insight.

\section{Recommendations for future IM pediatric programs}

The current findings suggest that the existence of biomedical evidence alone does not lead to the uptake of an IM program-it is the critical engagement with that evidence and the word of mouth and discussion of anecdotal evidence that lead to demand and community support for a program. With key decision-makers on board, such as Michelle's department head promoting her acupuncture practice or Albert's support for Sarah initiating the IM pilot, opportunities for CIM dissemination open up. Research in adult contexts has also noted the importance of key decisionmakers in implementing IM programs. ${ }^{45}$ This suggests the importance of stakeholder engagement in the future of CIM dissemination and implementation.

Education and advocacy efforts for pediatric CIM should be strategically aimed at administrators, providers, parents, and patients with a focus on maximizing engagement. Particularly in an inpatient setting, where time and attention can be limited, finding ways to engage attention, such as utilizing new media and technology, or offering opportunities to experience unfamiliar therapies, may be useful. As demonstrated here and through previous qualitative inquiries, trusted members of the community, be they influential providers, administrators, or parents, are arguably most powerful in the growth and promotion of IM in a given setting.

Overall, qualitative studies of CIM in adult and pediatric settings consistently refer to the importance of engaging with scientific evidence in establishing support for CIM, 7,25,46 and many make reference to the importance of providers' personal experience with CIM in garnering their support. ${ }^{27,47}$ Interest in CIM use has been growing in the pediatric medical community, with survey findings leading to increased education and dissemination efforts, and continued focus on CIM efficacy research in the pediatric context. ${ }^{48-51}$

Less explored in pediatric CIM research is the unique role of parents in critically appraising evidence, and the range of proclivity for parents to engage based on a number of factors, including the severity and acuity of their child's condition, and their own health care practices. ${ }^{52}$ In the current study, while some families did use scientific evidence to inform decision-making, the majority relied on providers to guide discussion of evidence, suggesting the need to prioritize new approaches to parent and patient engagement in the pediatric CIM research agenda.

The themes presented here align with previous qualitative findings in adult and pediatric settings. Hence, the types of thinking applied by study participants provide a framework that may be useful to future researchers, educators, and providers in the field of IM. Examples of critical thinking, ${ }^{46,47}$ relying on others for evidence, ${ }^{7,44,53,54}$ and reactionary thinking ${ }^{27}$ have been demonstrated in other adult and some pediatric qualitative studies of IM, although they are not labeled as such. Few qualitative inquiries in CIM include the perspectives of multiple constituencies, including health care providers, parents, patients, and administrators. Therefore, the findings presented in this study illuminate themes found elsewhere, but from less-documented perspectives, and suggest the need for future studies to continue to include this diversity of input.

Future interventions for uptake of IM may consider the contexts of all stakeholders and use the framework provided here to help tailor interventions and educational materials to maximally engage providers, parents, patients, and administrators. The focus of CIM research has been largely on clinical trials, designed primarily to establish the efficacy of CIM practices or to understand mechanisms. As the field of CIM has gained traction, larger trials are now being funded with increased emphasis on patient centered outcomes and dissemination and implementation. ${ }^{55}$

To tailor IM interventions to the specific needs of a given setting, implementation science methods and principles of community-based participatory research will be useful in designing sustainable programs with community buy-in. Ideally this would include giving stakeholders tools and opportunity to engage critically with IM.

\section{Conclusion}

CIM is a growing force in pediatric health care, and particularly in pain management. With the growing awareness of the opioid epidemic, health care organizations are working to incorporate nonpharmacologic pain management into their treatment plans. As hospitals seek to provide the best possible care for their patients and mitigate opioid misuse, more health care organizations will look to CIM to assist in the provision of pain management and the mitigation of risk. Biomedical environments seeking to integrate CIM into pain treatment regimens will need to engage all relevant stakeholders in building education, clinical training, and research programs that are critically informed about the context and evidence for CIM.

\section{Acknowledgments}

This research was supported by a Dissertation Award from the University of Texas Health Science Center at Houston School of Public Health (UTHealth). I.R.'s contribution to this article was partially supported by a T32 Fellowship from the National Center for Complementary and Integrative Health (5T32AT00378-12).

\section{Author Disclosure Statement}

No competing financial interests exist.

\section{References}

1. Friedrichsdorf SJ, Postier A, Eull D, et al. Pain outcomes in a US children's hospital: A prospective cross-sectional survey. Hosp Pediatr 2015;5:18-26.

2. Hechler T, Kanstrup M, Holley AL, et al. Systematic review on intensive interdisciplinary pain treatment of children with chronic pain. Pediatrics 2015;136:115-127.

3. Brooks MR, Golianu B. Perioperative management in children with chronic pain. Paediatr Anaesth 2016;26:794806.

4. Centers for Disease Control and Prevention (CDC). Vital signs: Overdoses of prescription opioid pain relievers- 
United States, 1999-2008. MMWR Morb Mortal Wkly Rep 2011;60:1487-1492.

5. Knipper E, Banta-Green CJ, Jimenez N. Opioid use disorder and misuse: A review of the epidemiology and medical implications for pediatric anesthesiologists. Paediatr Anaesth 2017;27:1070-1076.

6. Centers for Disease Control and Prevention (CDC). Vital signs: Unintentional injury deaths among persons aged 0 19 years - united states, 2000-2009. MMWR Morb Mortal Wkly Rep 2012;61:270-276.

7. Witt CM, Holmberg C. Changing academic medicine: Strategies used by academic leaders of integrative medicine-A qualitative study. Evid Based Complement Alternat Med 2012;2012:652546.

8. NCCAM Clearinghouse. Complementary, alternative, or integrative health: What's in a name? Updated July 2018. Online document at: http://nccam.nih.gov/health/whatiscam, accessed February 1, 2019.

9. Clarke TC, Black LI, Stussman BJ, et al. Trends in the use of complementary health approaches among adults: United states, 2002-2012. Natl Health Stat Report 2015; $1-16$.

10. Black LI, Clarke TC, Barnes PM, et al. Use of complementary health approaches among children aged 4-17 years in the United States: National health interview survey, 2007-2012. Natl Health Stat Report 2015;1-19.

11. Groenewald CB, Beals-Erickson SE, Ralston-Wilson J, et al. Complementary and alternative medicine use by children with pain in the United States. Acad Pediatr 2017; 17:785-793.

12. Thrane S. Effectiveness of integrative modalities for pain and anxiety in children and adolescents with cancer: A systematic review. J Pediatr Oncol Nurs 2013;30:320-332.

13. Dusek JA, Finch M, Plotnikoff G, et al. The impact of integrative medicine on pain management in a tertiary care hospital. J Patient Saf 2010;6:48-51.

14. Abrams DI, Dolor R, Roberts R, et al. The BraveNet prospective observational study on integrative medicine treatment approaches for pain. BMC Complement Altern Med 2013;13:146.

15. Weeks J. Influential U.S. medical organizations call for insurance coverage of non-pharmacologic approaches to pain. J Altern Complement Med 2016;22:947-949.

16. Weeks J. The joint commission moves integrative approach ahead of pharmaceuticals for pain management ... plus more. Integr Med (Encinitas) 2015;14:14-16.

17. Kuttner L. Pediatric hypnosis: Pre-, peri-, and postanesthesia. Paediatr Anaesth 2012;22:573-577.

18. Uman LS, Birnie KA, Noel M, et al. Psychological interventions for needle-related procedural pain and distress in children and adolescents. Cochrane Database Syst Rev 2013;CD005179.

19. Mandel S, Davis B, Secic M. Effects of music therapy on patient satisfaction and health-related quality of life of hospital inpatients. Hosp Top 2014;92:28-35.

20. Bradt J, Dileo C, Grocke D, Magill L. Music interventions for improving psychological and physical outcomes in cancer patients. Cochrane Database Syst Rev 2011; CD006911.

21. Yinger O, Gooding L. A systematic review of music-based interventions for procedural support. J Music Ther 2015;52: $1-77$.

22. Golianu B, Yeh AM, Brooks M. Acupuncture for pediatric pain. Children (Basel) 2014;1:134-148.
23. Yang C, Hao Z, Zhang LL, Guo Q. Efficacy and safety of acupuncture in children: An overview of systematic reviews. Pediatr Res 2015;78:112-119.

24. Highfield E, McLellan M, Kemper K, et al. Integration of complementary and alternative medicine in a major pediatric teaching hospital: An initial overview. J Complement Altern Med 2005;11:373-380.

25. Eckert M, Amarell C, Anheyer D, et al. Integrative pediatrics: Successful implementation of integrative medicine in a German hospital setting-concept and realization. Children (Basel) 2018;5. pii: E122.

26. Vohra S, Feldman K, Johnston B, et al. Integrating complementary and alternative medicine into academic medical centers: Experience and perceptions of nine leading centers in North America. BMC Health Serv Res 2005;5: 78.

27. Salkeld EJ. Framework negotiations: Diagnostic insights among alternative medical practitioners participating in integrative medicine case conferences. Med Anthropol Q 2014;28:44-65.

28. Smithson J, Paterson C, Britten N, et al. Cancer patients' experiences of using complementary therapies: Polarization and integration. J Health Serv Res Policy 2010;15 Suppl 2: 54-61.

29. Hollenberg D, Muzzin L. Epistemological challenges to integrative medicine: An anti-colonial perspective on the combination of complementary/alternative medicine with biomedicine. Health Sociol Rev 2010;19:34-56.

30. Frenkel M, Ben-Arye E, Geva H, Klein A. Educating CAM practitioners about integrative medicine: An approach to overcoming the communication gap with conventional health care practitioners. J Altern Complement Med 2007; 13:387-391.

31. Gray B, Orrock P. Investigation into factors influencing roles, relationships, and referrals in integrative medicine. J Altern Complement Med 2014;20:342-346.

32. Frank L. The PCORI perspective on patient-centered outcomes research. JAMA 10;312:1513.

33. Robinson N. Developing a decision-making model on traditional and complementary medicine use for children. Eur J Integr Med 04;1:43-50.

34. Crabtree BF, Miller WL. Doing Qualitative Research, vol. 3. Newbury Park: Sage Publications, 1992:3.

35. Roth I. Ethnography of Integrative Pain Management at a Large Urban Pediatric Hospital. [Doctor of Public Health (DrPH)]. Houston, TX: University of Texas School of Public Health; 2017.

36. Wolcott H. Ethnography: A Way of Seeing, 2nd ed. United Kingdom: AltaMira Press, 2008.

37. Schensul JJ, LeCompte MD. The Ethnographer's Toolkit. Walnut Creek, Calif: AltaMira Press, 1999.

38. Green J, Thorogood N. Qualitative Methods for Health Research. Sage, 2013, accessed February 1, 2019.

39. Pioneer Support Services I. Pioneer transcription services: Always accurate transcripts. Updated 2008. Online document at: www.pioneer-transcription-services.com

40. Spradley JP. The Ethnographic Interview. New York: Holt, Rinehart and Winston, 1979.

41. Gale NK, Heath G, Cameron E, et al. Using the framework method for the analysis of qualitative data in multidisciplinary health research. BMC Med Res Methodol 2013;13:117.

42. Saldaña J. The Coding Manual for Qualitative Researchers, 2nd ed. Los Angeles: SAGE, 2013. 
43. Joseph-Williams N, Elwyn G, Edwards A. Knowledge is not power for patients: A systematic review and thematic synthesis of patient-reported barriers and facilitators to shared decision making. Patient Educ Couns 2014;94:291309.

44. Shuval JT. Integrating CAM and biomedicine in primary care settings physicians' perspectives on boundaries and boundary work. Qual Health Res 2012;22:1317-1329.

45. Coulter I, Hilton L, Ryan G, et al. Trials and tribulations on the road to implementing integrative medicine in a hospital setting. Health Sociol Rev 2008;17:368-383. http://search .ebscohost.com/login.aspx?direct $=$ true $\& d b=a 9 h \& A N=35886$ $701 \&$ site $=$ ehost-live.

46. Anheyer D. "I think you can achieve quite a lot if all of the staff stands behind it"-A qualitative study about the experience, knowledge and application of complementary therapies and integrative medicine in pediatrics. Complement Ther Med 2018;41:186-191.

47. Taylor SL. Challenges and strategies for implementing battlefield acupuncture in the veterans administration: A qualitative study of provider perspectives. Med Acupunct 2018;30:252-261.

48. Kemper KJ, O'Connor KG. Pediatricians' recommendations for complementary and alternative medical (CAM) therapies. Ambul Pediatr 2004;4:482-487.

49. Kemper K, Vohra S, Walls R. The use of complementary and alternative medicine in pediatrics. Pediatrics 2008;122: 1374-1386.

50. McClafferty H, Vohra S, Bailey M, et al. Pediatric integrative medicine. Pediatrics 2017;140:e20171961.
51. Esparham A, Misra S, Sibinga E, et al. Pediatric integrative medicine: Vision for the future. Children (Basel) 2018;5: 111.

52. Gagnon EM, Recklitis CJ. Parents' decision-making preferences in pediatric oncology: The relationship to health care involvement and complementary therapy use. Psychooncology 2003;12:442.

53. Mittring N, Perard M, Witt CM. Corporate culture assessments in integrative oncology: A qualitative case study of two integrative oncology centers. Evid Based Complement Alternat Med 2013;2013:316950.

54. Sharf BF, Geist Martin P, Cosgriff-Hernandez KK, Moore J. Trailblazing healthcare: Institutionalizing and integrating complementary medicine. Patient Educ Couns 2012;89: 434-438.

55. Gardiner P, Lestoquoy AS, Gergen-Barnett K, et al. Design of the integrative medical group visits randomized control trial for underserved patients with chronic pain and depression. Contemp Clin Trials 2017;54:25-35.

Address correspondence to: Isabel Roth, DrPH

Program on Integrative Medicine

Department of Physical Medicine and Rehabilitation University of North Carolina at Chapel Hill School of Medicine Wing $D, R m 186$ Chapel Hill, NC, 27514

E-mail: iroth@email.unc.edu

\section{Appendices}

\section{Appendix 1: Interview Guide for Caregivers and Children aged 7-17}

Open-ended interviews were conducted in patient's rooms. The following guide was adjusted to suit the flow of the conversation, with additional questions added or removed as needed.

We'll start with some basic questions about [your child]. How old is the child?

What is the child's gender?

What is the child's ethnicity?

What is the child's diagnosis and the source of the pain?

How long has the child been receiving treatment?

Now I'm going to ask you questions about your thoughts and experience about the care you've received at the hospital.

MINI TOUR: What are you in the hospital for?

MINI TOUR: How long have you been at the hospital? GRAND TOUR: Please tell me about the kind of pain you've been experiencing.

MINI TOUR: What do you think the source of your pain is?

MINI TOUR: Is it acute or chronic? Have you had the pain for a short time, or has it been going on for a while? GRAND TOUR: Tell me about your experience with the pain service. How has it been for you?
MINI TOUR: How long have you been receiving pain treatment (both here at the hospital and in general)?

GRAND TOUR: What kinds of things had you heard about pain treatment?

GRAND TOUR: What kinds of things have you heard about complementary therapies or integrative medicine (Like acupuncture, music therapy, medical hypnosis, or biofeedback)?

MINI TOUR: Are there other alternative ways you've heard about dealing with your pain?

GRAND TOUR: What kinds of pain treatment has your child (or YOU) received?

MINI TOUR: Has your child (or YOU) had any therapies (like acupuncture, biofeedback, medication hypnosis, music therapy, massage, or talk therapy) to treat the pain?

MINI TOUR: Has your child (or YOU) taken any medications to treat the (your) pain?

GRAND TOUR: Was it difficult to decide which pain treatment(s) to accept?

MINI TOUR: Why or why not?

GRAND TOUR: How did the provider talk to you about the pain treatments offered?

MINI TOUR: Was there any other kind of information you wish they had provided to help you understand the pain treatment options? 


\section{Appendix 2: Interview Guide for Providers}

The following guide was adjusted to suit the flow of the conversation, and additional questions added or removed as needed.

We'll start with some basic questions about you.

What is your gender?

What is your ethnicity?

What type of provider are you?

GRAND TOUR: Tell me about your experience with your work at the hospital. How has it been for you?

GRAND TOUR: What kinds of treatment do you provide?

MINI TOUR: Do you provide any therapies (such as acupuncture, biofeedback, medication hypnosis, music therapy, massage, or talk therapy) to treat pain?

GRAND TOUR: What kind of training (medical or otherwise) did you receive?

MINI TOUR: What did you learn about complementary and integrative medicine (CIM) in your training (if anything)?
MINI TOUR: What has your experience been with CIM? GRAND TOUR: What kinds of things have you heard about complementary therapies or integrative medicine?

MINI TOUR: How do you think these therapies can be integrated into the hospital setting?

GRAND TOUR: Do you think patients find it difficult to decide which pain treatment(s) to accept?

MINI TOUR: Why or why not?

GRAND TOUR: How do you talk to patients about their pain treatment options?

MINI TOUR: What do you think they find most helpful or the least helpful about the information you share with them? GRAND TOUR: What other kinds of health care providers do you work with?

MINI TOUR: What do you think works best about your team? MINI TOUR: Is there anything that other providers don't understand about what you do?

MINI TOUR: How do you think team dynamics could be improved? 